\title{
Influence of docosahexaenoic acid on the concentration of fatty acids and volatile fatty acids in rumen fluid analysed by a rumen-simulation techniques*
}

\author{
L. Liu, J.Q. Wang'1, D.P. Bu1, S.J. Liu, S. Liang, K.L. Liu, H.Y. Wei \\ and L.Y. Zhou
}
State Key Laboratory of Animal Nutrition, Institute of Animal Science, Chinese Academy of Agricultural Sciences Beijing 100193, P.R.. China

(Received 23 March 2008; revised version 12 November 2008; accepted 23 January 2009)

\begin{abstract}
Changes in the composition and content of fatty acids (FA), including volatile fatty acids (VFA), in rumen fluid were analysed by a rumen-simulation technique (RUSITEC) following dietary supplementation with docosahexaenoic acid $\left(\mathrm{C}_{22: 6}\right.$; DHA). Three different diets were tested: basal diet (CON, 60 : 40 forage to concentrate), basal diet plus $0.65 \%$ DHA (Trt1) and basal diet plus $1.30 \%$ DHA (Trt2). The experiment lasted 7 days (6 days for adaptation and 1 day for sampling). Culture fluid was collected every $2 \mathrm{~h}$ over a 12 -h period on the last day of the experimental period. Compared to $\mathrm{CON}$, the stearic $\left(\mathrm{C}_{18: 0}\right)$ concentration decreased by 76.93 and $80.35 \%$ when Trt 1 and Trt2 were administered, respectively $(\mathrm{P}<0.01)$. Whereas the trans-vaccenic acid (trans- $11 \mathrm{C}_{18: 1}$; TVA) concentration increased by 185 and 126\% compared to CON when Trt1 and Trt 2 were administered, respectively, the cis-9, trans-11 conjugated linoleic acid (CLA) concentration increased by 111 and $142 \%$. Compared to CON, addition of DHA changed the profiles of volatile fatty acids (VFA) in culture fluid, in which propionate content increase in replacement of acetate decrease. The concentrations of volatile fatty acids (VFA), TVA, and cis-9, trans-11 CLA were affected by the sampling time. These data indicate that dietary supplementation with DHA alters the VFA and FA content of culture fluid; however, these data should be replicated in vivo.
\end{abstract}

KEY WORDS: docosahexaenoic acid, trans-vaccenic acid, cis-9, trans-11 conjugated linoleic acid, volatile fatty acids, rumen-simulation technique

\footnotetext{
* Supported by the Grant Agency of the Ministry of Science and Technology of People Republic of China. Funded in part by the Ministry of Science and Technology (2006BAD04A03, 2006BAD12B08) and Ministry of Agriculture (Nyhyzx07-036)

${ }^{1}$ Corresponding author: e-mail: jqwangcaas@gmail.com; burdenpan@gmail.com
} 


\section{INTRODUCTION}

Conjugated linoleic acid (CLA) is a mixture of positional and geometrical isomers of linoleic acid with conjugated double bonds (Ip et al., 1999). The cis-9, trans-11 isomer of CLA has received considerable attention in recent years because of numerous potential health benefits (Belury, 1995). Recent studies have indicated that most of the cis-9, trans-11 CLA (78-93\%) in milk fat is derived from trans11C18:1 (TVA) in the mammary gland by delta-9 desaturase (Piperova et al., 2002). Therefore, increasing TVA production in the rumen would be the most feasible approach to enhance the milk fat $c i s-9$, trans-11 CLA content.

Previous reports have shown that the level ofTVAin rumen fluid can be increased significantly by adding fish oil to the diet (Whitlock et al., 2002; AbuGhazaleh et al., 2003), and these findings led AbuGhazaleh et al. (2001) to hypothesize that a component in fish oil may have stimulated ruminal TVA production from other sources of unsaturated fatty acids (FA). Subsequently, AbuGhazaleh and Jenkins (2004) discovered that the TVA content was significantly increased by adding highly purified DHA to a mixed ruminal culture after $24 \mathrm{~h}$ of cultivation, and they suggested that the omega-3 FA (e.g., DHA) in fish oil played a key role in enhancing trans-C18:1 production in the rumen, especially TVA. Nevertheless, it was reported that DHA could not form CLA and TVA directly in the rumen (Wonsil et al., 1994). There existed some studies about the effect of fish oil or DHA on FA profiles in mixed culture, but these results were not consistent (Whitlock et al., 2002; AbuGhazaleh et al., 2003; Wasowska et al., 2006). In the meanwhile, most of these studies involved the short-term addition of oil to a culture flask, and few considered changes in the parameters of ruminal fermentation when a high concentration of DHA was used. Thus, the objectives of this study were to examine the FA profile and volatile fatty acid (VFA) content in culture fluid following dietary supplementation with DHA by a rumen-simulation technique (RUSITEC).

\section{MATERIAL AND METHODS}

Docosahexaenoic acid was purchased from Hebei Haiyuan Chemical Company ( $85 \%$ purity; Hebei Province, P.R. China). The RUSITEC apparatus consisted of nine vessels with an effective volume of 21 , and the incubation procedure was as previously described (Mohammed et al., 2004). Inoculum fluid was obtained $3 \mathrm{~h}$ after morning feeding from four ruminally fistulated lactating Holstein dairy cows fed a TMR composed of $60 \%$ concentrate mixture, $20 \%$ maize silage and $20 \%$ lucerne hay. The fermenters were randomly assigned to the control (basal 
Table 1. Ingredients and chemical composition of the basal diet and its derivatives

\begin{tabular}{lccc}
\hline \multirow{2}{*}{ Ingredients } & \multicolumn{3}{c}{ Treatment $^{1}$} \\
\cline { 2 - 4 } \% of DM basis & Trt1 & Trt2 \\
lucerne hay & 20 & 20 & 20 \\
chinese wild rye & 40 & 40 & 40 \\
maize & 17.5 & 15.5 & 12.2 \\
wheat bran & 3 & 3 & 3 \\
soyabean meal & 10 & 11 & 12 \\
cotton seed meal & 8 & 9.35 & 10 \\
calcium carbonate & 0.6 & 0.6 & 0.6 \\
calcium phosphate & 0.6 & 0.6 & 0.6 \\
sodium chloride & 0.3 & 0.3 & 0.3 \\
DHA & $n d^{2}$ & 0.65 & 1.30 \\
Chemical composition, $\%$ DM & & & \\
DM & & 91.13 & 91.31 \\
crude protein & 13.89 & 13.73 & 13.90 \\
ether extract & 2.79 & 4.71 & 6.60 \\
NDF & 39.97 & 39.72 & 39.45 \\
ADF & 24.80 & 24.73 & 24.70 \\
Ca & 0.81 & 0.81 & 0.82 \\
P & 0.42 & 0.41 & 0.41 \\
\hline
\end{tabular}

${ }^{1} \mathrm{CON}$ - basal diet; Trt1 - CON with $0.65 \%$ DHA; Trt2 - CON with $1.3 \%$ DHA; ${ }^{2}$ nd - not detected

diet without DHA; CON; Table 1); CON with $0.65 \%$ DHA (Trt1), and CON with $1.3 \%$ DHA (Trt2), three fermenters were planned for each treatment as replicates. The experimental period consisted of $6 \mathrm{~d}$ for adaptation, followed by $1 \mathrm{~d}$ for sampling.

Approximately $2000 \mathrm{ml}$ of rumen fluid were collected from each cow $3 \mathrm{~h}$ after morning feeding. At the same time about $400 \mathrm{~g}$ rumen digesta was collect from four different positions. Rumen fluid and digesta were mixed into one bottle and transferred to laboratory under anaerobic condition at $39^{\circ} \mathrm{C}$. The mixture was strained through four layers of cheesecloth before distributed to each fermenter. Each fermenter was filled with $800 \mathrm{ml}$ of rumen fluid and $800 \mathrm{ml}$ of prewarmed McDougall buffer (McDougall, 1948). The fermenters, which were maintained at $39^{\circ} \mathrm{C}$, were mixed constantly at $15 \mathrm{rpm}$ via an impeller stirrer and purged with $\mathrm{CO}_{2}$ gas. The $\mathrm{pH}$ in each fermenter was regulated by the addition of buffer through a tube connected to a pump. Each fermenter was replenished daily with the respective treatment diet at 08.00 and $20.00 \mathrm{~h}$.

On the last day of the experimental period, culture fluid was collected using an injection syringe from the $\mathrm{CO}_{2}$ airscoop at time $0 \mathrm{~h}$ (before morning replenishing), 
and subsequent samples were collected 2, 4, 6, 8 and $10 \mathrm{~h}$ later. A pH meter (model 370 , Jenway, Essex, UK) was used to determine the $\mathrm{pH}$ of the samples, which were then stored at $-20^{\circ} \mathrm{C}$ until further analysis.

The culture fluid was thawed and then centrifuged at $1,000 \mathrm{~g}$ for $10 \mathrm{~min}$, and $1 \mathrm{ml}$ of the supernatant was transferred into an Eppendorf tube. The fluid was then mixed with $0.2 \mathrm{ml}$ of $25 \%$ metaphosphoric acid and incubated for $30 \mathrm{~min}$. The concentration of VFA was subsequently analysed by gas chromatography (model 6890, Series II; Hewlett Packard Co., Avondale, PA) using the method of Mohammed et al. (2004). For culture fluid FA analysis, chloroform/methanol (v/v; 2:1) was prepared to extracted the rumen fluid FA (Kramer et al., 2001), chloroform which contained FA was dried by nitrogen gas, and then the FA in the culture fluid was methylated according to Kramer et al. (1997). Separation of the individual FA in the samples was achieved using a gas chromatograph (model 6890, Series II; Hewlett Packard Co.) fitted with a flame-ionization detector and a fused-silica HP-88 capillary column $(100 \mathrm{~m}, 0.25 \mathrm{~mm}$ i.d., $0.20 \mu \mathrm{m}$ film; Supelco Inc., Bellefonte, PA). A sample containing FA methyl esters in hexane $(1 \mu \mathrm{l})$ was injected by automatic sampling with split injection. The oven was initially kept at $120^{\circ} \mathrm{C}$ for $10 \mathrm{~min}$, then heated at $3.2^{\circ} \mathrm{C} / \mathrm{min}$ to $230^{\circ} \mathrm{C}$ and held for $35 \mathrm{~min}$. The injector temperature was maintained at $250^{\circ} \mathrm{C}$, while the detector was kept at $300^{\circ} \mathrm{C}$; the total running time was approximately $80 \mathrm{~min}$. Heptadecanoic acid $\left(\mathrm{C}_{17: 0}\right)$ was used as a quantitative internal standard. Each peak was identified using FA methyl esters (Nu-Chek Prep, Elysian, MN; Matreya, Pleasant Gap, PA; and 37 Component FAME mix, Supelco). The percentage of each FA was calculated by dividing the area under the FA peak (minus the area under the peak for heptadecanoic acid) by the sum of the areas under all of the reported peaks. All results are reported as $\mathrm{g} / 100 \mathrm{~g}$ of FA methyl esters.

The data were analysed using the PROC MIXED procedure of SAS 8.2 (SAS Inst. Inc. Cary, NC). Each fermenter was defined as a random effect, while the treatment and sampling times were defined as fixed effects. For statistical analysis of the rumen fluid, the $\mathrm{pH}$, sampling time, and sampling time by treatment interaction were defined as fixed effects and analysed using repeated measures. Least squares means and pooled SEM are reported for all data. Significance was declared at $\mathrm{P}<0.05$.

\section{RESULTS}

As is shown in Table 2, $\mathrm{pH}$ value increased as the DHA addition level ascended $(\mathrm{P}<0.01)$. The concentration of acetate and butyrate was lowest for Trt2, middle for Trt1 and highest for CON $(\mathrm{P}<0.01)$. On the contrary, the 
Table 2. The effects of adding DHA on rumen fermentation

\begin{tabular}{lrrrrrrr}
\hline \multirow{2}{*}{ Item } & \multicolumn{3}{c}{ Treatment $^{1}$} & \multirow{2}{*}{ SEM } & \multicolumn{3}{c}{$\mathrm{P}$} \\
\cline { 2 - 3 } \cline { 7 - 8 } & CON & \multicolumn{1}{c}{ Trt1 } & \multicolumn{1}{c}{ Trt2 } & & Trt $^{2}$ & samT $^{3}$ & Trt* $^{*}$ samT $^{4}$ \\
\hline $\mathrm{pH}$ & $6.13^{\mathrm{b}}$ & $6.24^{\mathrm{b}}$ & $6.48^{\mathrm{a}}$ & 0.06 & $<0.0001$ & 0.0634 & 0.2420 \\
Acetate, $\mathrm{mM} / 1$ & $93.27^{\mathrm{a}}$ & $78.84^{\mathrm{b}}$ & $65.55^{\mathrm{c}}$ & 4.34 & $<0.0001$ & $<0.0001$ & 0.1108 \\
Propionate, $\mathrm{mM} / 1$ & $31.08^{\mathrm{b}}$ & $40.06^{\mathrm{a}}$ & $43.25^{\mathrm{a}}$ & 2.51 & $<0.0001$ & $<0.0001$ & 0.1865 \\
Butyrate, $\mathrm{mM} / 1$ & $21.92^{\mathrm{a}}$ & $18.50^{\mathrm{ab}}$ & $15.79^{\mathrm{b}}$ & 1.79 & 0.0071 & 0.0011 & 0.3393 \\
TVFA $^{5}, \mathrm{mM} / 1$ & 148.72 & 140.76 & 129.32 & 11.15 & 0.0808 & 0.0034 & 0.5802 \\
Acetate $:$ propionate & $3.01^{\mathrm{a}}$ & $1.97^{\mathrm{b}}$ & $1.52^{\mathrm{b}}$ & 0.10 & $<0.0001$ & 0.1528 & 0.3124 \\
\hline
\end{tabular}

note: the data are average of three fermenters for each treatment and carried out after $6 \mathrm{~d}$ adaptation using RUSITEC; ${ }^{\text {abc }}$ means in the same row with different superscripts within each group differ significantly; ${ }^{1} \mathrm{CON}$ - basal diet; Trt1 - CON with $0.65 \%$ DHA; $\operatorname{Tr} 2$ - CON with $1.3 \%$ DHA; ${ }^{2}$ Trt - experimental treatment; ${ }^{3} \mathrm{samT}$ - sampling time; ${ }^{4} \mathrm{Trt} * \mathrm{samT}$ - coeffect of treatment and sampling time; ${ }^{5}$ TVFA - total volatile fatty acids

concentration of propionate was highest for Trt2, middle for Trt1, lowest for CON $(\mathrm{P}<0.01)$. In the meanwhile, the concentration of each VFA in Trt1 and Trt2 was the lowest $4 \mathrm{~h}$ and $8 \mathrm{~h}$ after replenished and then increased $(\mathrm{P}<0.05)$ (Figure 1). However, the total production of VFA was unchanged $(\mathrm{P}>0.05)$ by the addition of DHA.

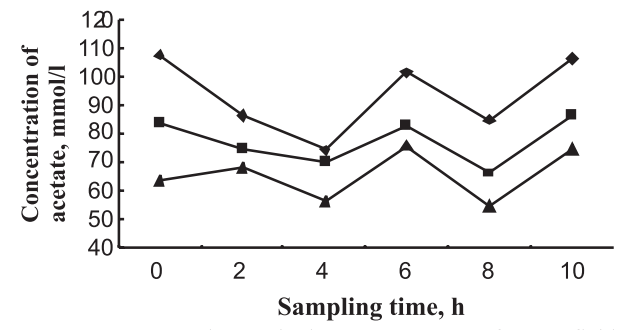

A. Changes in the acetate content of rumen fluid Trt: $\mathrm{P}<0.01$; time: $\mathrm{P}<0.01$; $\operatorname{Tr} \times$ time: $\mathrm{P}>0.05(\mathrm{SEM}=6.06)$

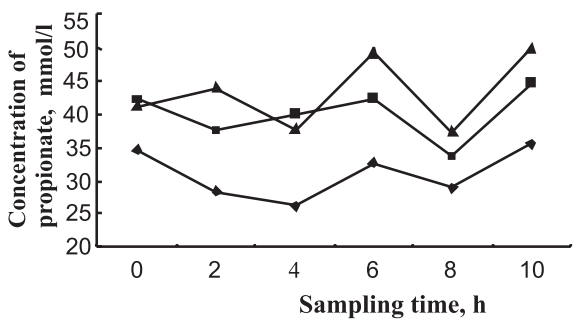

B. Changes in the propionate content of rumen fluid Trt: $\mathrm{P}<0.01$; Time: $\mathrm{P}<0.01$; Trt $\times$ time: $\mathrm{P}>0.05(\mathrm{SEM}=3.84)$

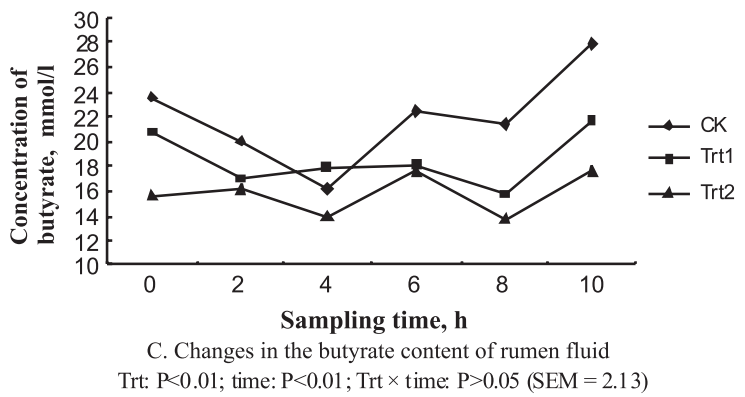

Figure 1. Changes in the concentration of three volatile fatty acids (acetate (A), propionate (B), and butyrate $(\mathrm{C})$ in culture fluid collected from before morning feeding to $10 \mathrm{~h}$ after feeding 
Dietary intake of DHA affected the concentration of FA in the culture fluid (Table 3 and Figure 2). The content of TVA in culture fluid was higher $(\mathrm{P}<0.01)$

Table 3. Effect of adding DHA on the fatty acid profile of the culture fluid

\begin{tabular}{|c|c|c|c|c|c|c|c|}
\hline \multirow{2}{*}{ Fatty acids } & \multicolumn{3}{|c|}{ Treatment $^{1}$} & \multirow{2}{*}{ SEM } & \multicolumn{3}{|c|}{$\mathrm{p}$} \\
\hline & $\mathrm{CON}$ & Trt1 & Trt2 & & $\mathrm{Trt}^{2}$ & $\mathrm{Sam}^{3}$ & Trt*samT $^{4}$ \\
\hline & \multicolumn{3}{|c|}{$\mathrm{g} / 100 \mathrm{~g} \mathrm{FAME}^{5}$} & & & & \\
\hline C6:0 & 0.03 & 0.02 & 0.02 & $\ldots$ & 0.0223 & $<0.0001$ & 0.1013 \\
\hline C14:0 & $0.04^{\mathrm{b}}$ & $0.04^{\mathrm{b}}$ & $0.06^{\mathrm{a}}$ & $\ldots$ & 0.0102 & $<0.0001$ & 0.3125 \\
\hline C14:1 & $n d^{6}$ & 0.01 & 0.01 & $\ldots$ & $<0.0001$ & 0.0070 & 0.0701 \\
\hline $\mathrm{C} 16: 0$ & 21.76 & 23.68 & 22.83 & 0.56 & $<0.0451$ & 0.0826 & 0.1020 \\
\hline C18:0 & $42.44^{\mathrm{a}}$ & $9.79^{\mathrm{b}}$ & $8.34^{\mathrm{b}}$ & 0.84 & $<0.0001$ & 0.2441 & 0.0146 \\
\hline t11C18:1 (TVA) & $9.72^{\mathrm{c}}$ & $27.71^{\mathrm{a}}$ & $21.98^{\mathrm{b}}$ & 1.79 & $<0.0001$ & 0.0301 & 0.1252 \\
\hline$c 9 \mathrm{C} 18: 1$ & $9.97^{\mathrm{b}}$ & $11.72^{\mathrm{a}}$ & $9.26^{\mathrm{b}}$ & 0.25 & $<0.0001$ & $<0.0001$ & 0.6004 \\
\hline $\mathrm{C} 18: 2$ & 0.04 & 0.04 & 0.03 & $\ldots$ & 0.0832 & $<0.0001$ & 0.3032 \\
\hline c9t11C18:2 (CLA) & $0.62^{\mathrm{c}}$ & $1.31^{\mathrm{ab}}$ & $1.50^{\mathrm{a}}$ & 0.12 & $<0.0001$ & $<0.0001$ & 0.5024 \\
\hline $\mathrm{C} 20: 5$ (EPA) & $0.08^{\mathrm{c}}$ & $0.77^{\mathrm{ab}}$ & $0.79^{\mathrm{a}}$ & 0.11 & $<0.0001$ & 0.7671 & 0.4518 \\
\hline C22:6 (DHA) & $0.14^{\mathrm{c}}$ & $1.75^{\mathrm{b}}$ & $2.56^{\mathrm{a}}$ & 0.15 & $<0.0001$ & 0.0001 & 0.0801 \\
\hline
\end{tabular}

note: the data are average of three fermenters for each treatment and carried out after $6 \mathrm{~d}$ adaptation using RUSITEC; ${ }^{\text {abc }}$ means in the same row with different superscripts within each group differ significantly; ${ }^{1} \mathrm{CON}$ - basal diet; Trt1 - CON with $0.65 \%$ DHA; Trt2 - CON with $1.3 \%$ DHA; ${ }^{2}$ Trt - experimental treatment; ${ }^{3} \mathrm{samT}$ - sampling time; ${ }^{4} \mathrm{Tr} t * \mathrm{samT}$ - coeffect of treatment and sampling time; ${ }^{5} \mathrm{FAME}$ - fatty acid methyl ester; ${ }^{6} \mathrm{nd}$ - not detected

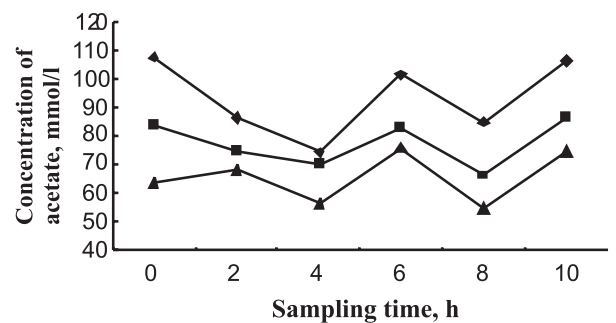

A. Changes in the acetate content of rumen fluid Trt: $\mathrm{P}<0.01$; time: $\mathrm{P}<0.01$; Trt $\times$ time: $\mathrm{P}>0.05(\mathrm{SEM}=6.06$

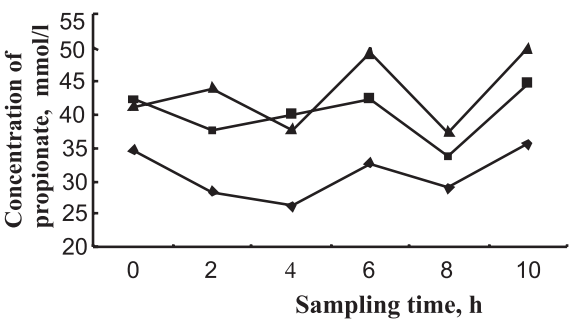

B. Changes in the propionate content of rumen fluid Trt: $\mathrm{P}<0.01$; Time: $\mathrm{P}<0.01$; Trt $\times$ time: $\mathrm{P}>0.05(\mathrm{SEM}=3.84)$

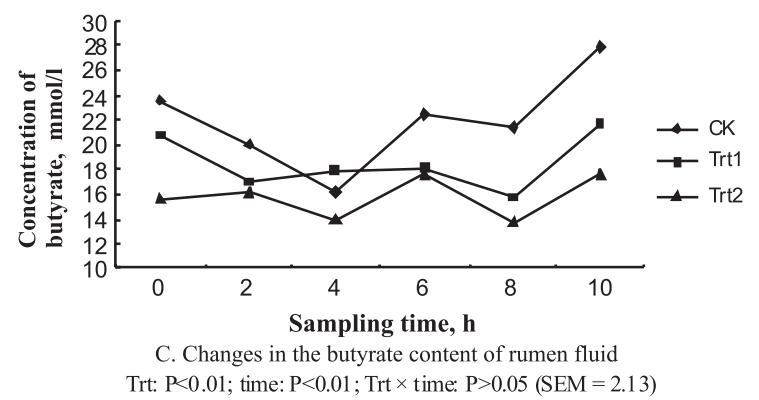

Figure 2. Changes in the concentration of selected fatty acids (C18:0, t11C18:1, and c9t11 CLA) in culture fluid collected from before morning feeding to $10 \mathrm{~h}$ after feeding 
by Trt1 and Trt2 compared with CON. Within each treatment, the content of TVA ascended slowly after feeding. On the contrary, the content of $\mathrm{C}_{18: 0}$ in culture fluid was higher $(\mathrm{P}<0.01)$ by $\mathrm{CON}$ compared with $\operatorname{Trt} 1$ and $\operatorname{Trt} 2$, and within each treatment the change trend was not significant $(\mathrm{P}>0.05)$. The cis-9, trans-11 CLA content was highest for Trt2 $(\mathrm{P}<0.01)$, middle for Trt1, and lowest for CON. Within either DHA treatment, the content of this CLA isomer was highest $3 \mathrm{~h}$ after feeding and then decreased. No interactions between the oil supplement and time after feeding were detected in the concentration of palmitic acid, oleic acid, and linoleic acid in the culture fluid.

\section{DISCUSSION}

In present study, dietary supplementation with DHA affected the $\mathrm{pH}$ of the culture fluid in an incremental fashion. This result is in agreement with those of Huhtanen and Kukkonen (1995) and Shingfield et al. (2003), which showed the effects of oil supplementation. A decrease in dry matter (DM) intake may be one cause of the increase in rumen fluid $\mathrm{pH}$ in response to oil seed consumption (Huhtanen et al., 1995). However, in our study, DM intake was held constant, hence, the observed increase in $\mathrm{pH}$ was not related to a decrease in DM intake. Lactobacillus in the rumen play a key role in $\mathrm{pH}$ change, thus, the addition of DHA to the diet may have negatively affected Lactobacillus growth, resulting in an increase in $\mathrm{pH}$. Since we did not measure Lactobacillus, additional studies are necessary to determine the effect of DHA on Lactobacillus.

Our data indicate that dietary supplementation with DHA affects the concentration of VFA in culture fluid. As the level of DHA was increased, the concentrations of acetate and butyrate decreased markedly, whereas the concentration of propionate increased. Dietary supplementation with DHA resulted in significantly different $(\mathrm{P}<0.01)$ proportions of acetate to propionate depending on the treatment, while no effect on the total VFA content was observed. This result is in agreement with that of Doreau and Chilliard (1997); however, Shingfield et al. (2003) reported that the propionate and butyrate contents increased following dietary fish oil supplementation, whereas the acetate content decreased. Such disparate data may result from different fish oil contents in the diet. Margarida et al. (2007) suggested that lipid supplementation might negatively affect microorganism growth in the rumen, leading to a decrease in fibre digestion. This might affect carbohydrate fermentation in the rumen, thereby changing the dynamics of rumen fermentation. Accordingly, the measured concentration of VFA in the rumen was altered.

Trans-11C18:1 concentration increases following dietary supplementation with fish oil (Shingfield et al., 2003; AbuGhazaleh et al., 2004), which is rich in long- 
chain unsaturated FA (e.g., DHA). In this study, the addition of DHA significantly increased the TVA and cis-9, trans-11 CLA content, in agreement with previous studies (AbuGhazaleh et al., 2002; Szolloskei et al., 2005). Moreover, Jalc et al. (2005) found that DHA significantly decreased the $\mathrm{C}_{18: 0}$ content, which is in agreement with our findings.

Fish oil can inhibit the biohydrogenation of unsaturated FA, thereby increasing the flow of trans $-\mathrm{C}_{18: 1}$ (Lee et al., 2005) and trans $-\mathrm{C}_{18: 2}$ (Loor et al., 2005) into the duodenum. Several in vitro studies have explored the mechanism underlying the effects of fish oil on the biohydrogenation of polyunsaturated FA in the rumen (Dohme et al., 2001). According to their results, DHA in fish oil inhibit the hydrogenation of unsaturated FA. In our study, we also found that the $\mathrm{C}_{18: 0}$ content in Trt1 and Trt2 was reduced by increases in DHA. This result is in agreement with that of Jalc et al. (2005), who reported that fish oil significantly lowered the $\mathrm{C}_{18: 0}$ content. AbuGhazaleh and Jenkins (2004) indicated that DHA in fish oil promotes TVA accumulation when incubated with linoleic acid. It has been suggested that DHA may restrain rumen bacterial growth, thereby decreasing the hydrogenation of unsaturated FA, resulting in an increased level of TVA and a decreased level of $\mathrm{C}_{18: 0}$ (Griinari and Bauman, 1999). Other researchers have reported that the accumulation of TVA caused by fish oil supplementation in the diet results from inhibition of a reductase in the rumen microorganisms that are responsible for the terminal hydrogenation of TVA to $\mathrm{C}_{18: 0}$ (Wasowska et al., 2006; AbuGhazaleh et al., 2007). Interestingly, we found that the TVA and cis-9, tran-11 CLA content was affected by sampling time. The cis- 9 , trans- 11 CLA content initially increased and then decreased over time, whereas the TVA concentration increased linearly. These data imply that DHA in the diet may promote CLA reductase activity in the rumen, allowing TVA to accumulate as the level of cis-9, trans-11 CLA is reduced (Fukuda et al., 2005). The amount of DHA in the Trt2 culture fluid was higher than that in the Trt1 culture fluid (data not shown), although AbuGhazaleh et al. (2004) showed that in Trt2 more DHA was transformed into other FA.

\section{CONCLUSIONS}

Our results show that adding DHA to the diet alters the VFA concentration, such that the amount of acetate and butyrate is decreased, while the level of propionate is increased. In addition, the $\mathrm{pH}$ of rumen fluid is increased by DHA. Adding DHA to a continuous culture of rumen fluid increased the concentration of TVA and cis-9, trans-11 CLA, and significantly lowered the $\mathrm{C}_{18: 0}$ content. DHA supplementation markedly affected the VFA and FA profile of rumen fluid; however, these data should be replicated in vivo. 


\section{ACKNOWLEDGMENTS}

The authors thank the staff of the ruminant nutrition lab at the Institute of Animal Science, Chinese Academy of Agricultural Science, for their assistance. We also acknowledge the kind contribution of A.F. Kertz to this work.

\section{REFERENCES}

AbuGhazaleh A.A., Jacobson B.N., 2007. Production of trans C18:1 and conjugated linoleic acid in continuous culture fermenters fed diets containing fish oil and sunflower oil with decreasing levels of forage. Animal 1, 660-665

AbuGhazaleh A.A., Jenkins T.C., 2004. Disappearance of docosahexaenoic and eicosapentaenoic acids from cultures of mixed ruminal microorganisms. J. Dairy Sci. 87, 645-651

AbuGhazaleh A.A., Schingoethe D.J., Hippen A.R., 2001. Conjugated linoleic acidand other beneficial fatty acids in milk fat from cows fed soybean meal, fish meal, or both. J. Dairy Sci. 84, 1845-1850

AbuGhazaleh A.A., Schingoethe D.J., Hippen A.R., Kalscheur K.F., 2003. Conjugated linoleic acid and vaccenic acid in rumen, plasma, and milk of cows fed fish oil and fats differing in saturation of 18 carbon fatty acids. J. Dairy Sci. 86, 3648-3660

AbuGhazaleh A.A., Schingoethe D.J., Hippen A.R., Kalscheur K.F., Whitlock L.A., 2002. Fatty acid profiles of milk and rumen digesta from cows fed fish oil, extruded soybeans or their blend. J. Dairy Sci. 85, 2266-2276

Belury M.A., 1995. Conjugated dienoic linoleate: a polyunsaturated fatty acid with unique chemical properties. Nutr. Rev. 53, 83-89

Dohme F., Machmüller A., Wasserfallen A., Kreuzer M., 2001. Ruminal methanogenesis as influenced by individual fatty acids supplemented to complete ruminant diets. Lett. Appl. Microbiol. 32, 47-51

Doreau M., Chilliard Y., 1997. Effects of ruminal or post-ruminal fish oil supplementation on intake and digestion in dairy cows. Reprod. Nutr. Develop. 37, 113-124

Fukuda S., Furuya H., Suzuki Y., Asanuma N., Hino T., 2005. A new strain of Butyrivibrio fibrisolvens that has high ability to isomerize linoleic acid to conjugated linoleic acid. J. Gen. Appl. Microbiol. Tokyo 51, 105-113

Griinari J. M., Bauman D. E., 1999. Biosynthesis of conjugated linoleic acid and its incorporation into meat and milk in ruminants. In: Advances in Conjugated Linoleic Acid Research, Vol. 1. M.P. Yurawecz, M.M. Mossoba, J.K.G. Kramer, M.W. Pariza, G.J. Nelson (Editors). AOCS Press, Champaign, IL, pp. 180-200

Huhtanen P., Kukkonen U., 1995. Comparison of methods, markers, sampling sites and models for estimating digesta passage kinetics in cattle fed at two levels of intake. Anim. Feed Sci. Tech. 52, 141-158

Ip C., Banni S., Angioni E., Carta G., McGinley J., Thompson H., Barbano D., Bauman D.E., 1999. Conjugated linoleic acid-enriched butter fat alters mammary glandmorphogenesis and reduces cancer risk in rats. J. Nutr. 129, 2135-2142

Jalc D., Szumacher-Strabel M., Potkanski A., Cieslak A., 2005. Effect of sunflower, linseed and fish oils on the production of trans fatty acids in vitro. Berl. Mün. Tierärztl. Wochenschr. 118, 430-435

Kramer J.K.G., Fellner V., Dugan M.E.R., Sauer F.D., Mossoba M.M., Yurawecz M.P., 1997. Evaluating acid and base catalysts in the methylation of milk and rumen fatty acids with special emphasis on conjugated dienes and total trans fatty acids. Lipids 32, 1219-1228 
Kramer J.K.G., Jiangqiang Z., 2001. Conjugated linoleic acid and octadecenoic acids: Extraction and isolation of lipids. Eur. J. Lipid Sci. Technol. 103, 594-632

Lee M.R.F., Tweed J.K.S., Moloney A.P., Scollan N.D., 2005. The effects of fish oil supplementation on rumen metabolism and the biohydrogenation of unsaturated fatty acids in beef steers given diets containing sunflower oil. Anim. Sci. 80, 361-367

Loor J.J., Ueda K., Ferlay A., Chilliard Y., Doreau M., 2005. Intestinal flow and digestibility of trans fatty acids and conjugated linoleic acids (CLA) in dairy cows fed a high-concentrate diet supplemented with fish oil, linseed oil, or sunflower oil. Anim. Feed Sci. Tech. 119, 203-225

Margarida R.G.M., Chaudhary L.C., Figueres L., Wallace R.J., 2007. Metabolism of polyunsaturated fatty acids and their toxicity to the microflora of the rumen. Anton. Leeuwenhoek 91, 303-314

McDougall E.I., 1948. The composition and output of sheep's saliva. Biochem. J. 43, 99-109

Mohammed N., Ajisaka N., Lila Z.A., Hara K., Mikuni K., Kanda S., Itabashi H., 2004. Effect of Japanese horseradish oil on methane production and ruminal fermentation in vitro and in steers. J. Anim. Sci. 82, 1839-1846

Piperova L.S., Sampugna J., Teter B.B., Kalscheur K.F., Yurawecz M.P., Ku Y., Morehouse K.M., Erdman R.A., 2002. Duodenal and milk trans octadecenoic acid and conjugated linoleic acid (CLA) isomers indicate that postabsorpative synthesis is the predominant source of cis-9containing CLA in lactating dairy cows. J. Nutr. 132, 1235-1241

Shingfield K.J., Ahvenjarvi S., Toivonen V., Arola A., Nurmela K.V.V., Huhtanen P., Griinari J.M., 2003. Effect of dietary fish oil on biohydrogenation of fatty acids and milk fatty acid content in cows. Anim. Sci. 77, 165-179

Szolloskei G., Wagner L., Nemeth S., Husveth F., 2005. In sacco studies of conjugated linoleic acid production from various oils in the rumen of sheep. Acta Vet. Hung. 53, 411-423

Wasowska I., Maia M.R.G., Niedzwiedzka K.M., Czauderna M., Ramalho Ribeiro J.M.C., Devillard E., Shingfield K.J., Wallace R.J., 2006. Influence of fish oil on ruminal biohydrogenation of C18 unsaturated fatty acids. Brit. J. Nutr. 95, 1199-1211

Whitlock L., Schingoethe D. J., Hippen A.R., Baer R.J., Ramaswamy N., Kasperson K.M., 2002. Fish oil and extruded soybeans fed in combination increase CLA in milk of dairy cows more than when fed separately. J. Dairy Sci. 85, 234-243

Wonsil B.J., Herbein J.H., Watkins B.A., 1994. Dietary and ruminally derived trans-18:1 fatty acids alter bovine milk lipids. J. Nutr. 124, 556-565 